\title{
Earl Howe: 'We've got to have a system in which everyone has confidence.'
}

Please send any ideas for feature articles for consideration to:

Ruth Doherty,

Managing Editor,

British Dental Journal

The Macmillan Building,

4-6 Crinan Street,

London,

N1 9XW

Email: r.doherty@nature.com

BDJ Managing Editor, Ruth Doherty, caught up with Earl Howe at the British Dental Conference and Exhibition held

in Manchester in April this year.

Lord Howe has been Parliamentary UnderSecretary of State in the Department of Health since May 2010. He is an elected hereditary peer under the provisions of the House of Lords Act 1999. From 1997 to 2010 he was opposition spokesman for Health and Social Services in the House of Lords and has held many other positions including whip in the House of Lords, Parliamentary Secretary (Lords) at the Ministry of Agriculture, Fisheries and Food and Parliamentary Under-Secretary of State at the Ministry of Defence.

\section{How do you feel the new dental contract pilots are progressing?}

I'm very encouraged by the progress so far. We are committed to bringing in a new contract based on three elements: registration, capitation and quality. The point of that is to do the two things that dentists most care about, as do we, which is to increase access to NHS dentistry and to improve oral health. The pilots are designed to test out the various elements that we need in the new contract. They have been running in 70 practices since last September so we have had six months worth of data. It is too early for me to tell you what the findings from the data are but the informal feedback that I have had suggests that the approach we are taking is popular with dentists, and indeed patients. The decision we took earlier this year to extend the pilots to March 2013, I think, went down well.
What challenges do you forsee in implementing the new dental contract once the pilots are finished?

Obviously it is too soon for me to be specific about how the contract will look and indeed what the timing will be. One of the challenges we are finding is that in some of the pilots dentists are encountering difficulties with the software. We are addressing those. One has to recognise that this is part of the reason for having pilots: you discover things that don't go quite according to plan and the whole point is to sort these things out. The pilots are providing us with very rich data - what that implies is that dentists are spending quite a lot of time with their patients and maybe the throughput of patients isn't as rapid as they would like. We will have to address that and iron out any of the clunky elements of the process so that this is not a cumbersome nor burdensome practice but quite the reverse. We've got to have a system in which everyone has confidence.

\section{What is the future for dentists in the UK?}

Well, I believe dentistry has a very robust future. We are committed to growing access to NHS dentistry. In fact the latest figure I have is that 991,000 more patients have seen an NHS dentist since May 2010 which is very encouraging. [This figure has now reached 1.12 million as of the 17th May 2012. ${ }^{1}$ ] I think more broadly, as I said in my speech [at British Dental
Conference in Manchester], the availability of dental services and dental health are very important for the population. This situation will not change and it will drive growth in both the NHS and the private sector. Good oral health is very much the norm and is to be expected. I think all that provides a pretty solid underpinning for dentists' careers in this country. I am minister for England, I cannot, of course, speak for the other parts of the UK, but I think the same basic drivers apply everywhere.

\section{What's the biggest challenge facing your department in providing the best quality dental care?}

We've made three specific commitments in relation to dentistry: to improve the availability of dental services, to improve the oral health of the population with a particular focus on children and to develop the new dental contract. And I think we are making progress in all of these areas. The biggest challenge has to be the inequalities in oral health, particularly in children. We are piloting new ways to support dentists to identify children who are at most risk of tooth decay to get those children the care and preventive advice they need. That involves more than just dentists, it involves engaging with schools, local authorities, the wider health community and general medical practice. So that is work in progress and it is desperately needed. 
Child dental neglect is coming to the fore as a serious problem in the UK - do you think that school dental-screening would help reduce its prevalence?

I know that dental screening has been suggested as a way of addressing poor oral health in children. Actually the evidence shows it isn't a very cost-effective way of going about things. We've got to remember that the majority of children have good oral health. A straightforward screening programme is a rather blanket approach. It is not effective according to the evidence we have got. And even if you do identify, through screening, a child who requires dental care there are all sorts of other obstacles to overcome. For example, parental consent is difficult to obtain from parents who are neglecting their children as they have to return consent forms, but even if you get the consent you then have the further barrier of getting them to attend appointments. We have to be cleverer about this, more subtle. So PCTs around the country are focusing their efforts, jointly with local authorities, on a much more comprehensive approach targeting those families who are least likely to seek help for themselves. We've been collecting evidence of how that approach is working so that we can share it more widely. I'm looking forward to seeing the fruits of that research. What I was very pleased to see recently was the inclusion of an indicator in the public health outcomes framework for local authorities on levels of dental caries in 5-year-olds because I think that really will act as a driver for improvement in children's oral health.

\section{There has been considerable opposition to the Heath and Social Care Bill from many healthcare groups - what is your response to their arguments?}

Well, I hope that those who have expressed their doubts and reservations about the Health and Social Care Bill will come to change their minds. The changes set out in the Act in relation to dentistry have been warmly welcomed by most dental stakeholders, including the Chief-Executive of the BDA, and the decision to commission all dental services directly through the NHS commissioning board was particularly welcomed. I think this does give us an opportunity to really integrate effectively dental services provided in high street practices, salaried services, dental hospitals and dental schools. We will continue to work with those who remain unhappy with this approach and to understand their concerns. The detailed arrangements for dentistry will be ones that we will work through with the dental community more generally.

\section{Any dentistry experiences you'd like to share with the $B D J$ readers?}

Recounting this story doesn't reflect particularly well on me because it concerns someone else's misfortune. However, I heard not long ago of an incident at a Buckingham Palace garden party held on a hot July day. In the aftermath of the event the staff were clearing up following the departure of the guests and as they were doing so one of them discovered, concealed behind a tree, a large and gooey meringue in which was embedded a brand new set of dentures! It takes little imagination to picture the blind panic in the mind of the denture owner, perhaps even in the immediate presence of royalty, which led to them having to abandon their set of teeth in the home of the sovereign.

1. Department of Health Press Release. Extra one million people now seeing NHS dentist since May 2010. Available online at http://mediacentre.dh.gov. uk/2012/05/17/extra-one-million-people-nowseeing-nhs-dentist-since-may-2010 (accessed May 2012). 